\title{
Outcomes and savings associated with the Quality Parenting Initiative
}

\author{
Mary Eschelbach Hansen ${ }^{1}$, Ashley Provencher ${ }^{2}$, Brian T. Yates ${ }^{3}$
}

\begin{abstract}
Though several training and support programs for foster carers improve child behaviors, few have been shown to have a large impact on child welfare outcomes such as permanency. Additionally, most training and support programs are expensive. The Quality Parenting Initiative (QPI) aims to improve outcomes at low cost by empowering foster carers as well as caseworkers. This paper uses administrative data to show that the earliest implementation of QPI shortened stays in care for children who were reunified. Savings from shorter stays in care are estimated to be more than three times greater than expenditures.
\end{abstract}

Keywords:child welfare outcomes; foster carers; parenting training

1. Professor of Economics, American University, USA

2. Associate Professor of Economics, Sienna College, USA

3. Professor of Psychology, American University, USA

Address for correspondence: mhansen@american.edu

Date of first (online) publication: 19th September 2019 


\section{Introduction}

Child welfare systems worldwide report persistent difficulties in achieving permanency for children in foster care (for a recent review, see Bell and Ramono, 2017). In the United States, the Child and Family Services Reviews performed by the federal government's Children's Bureau make it clear that child welfare outcomes vary widely across states. For example, in the second round of reviews, the percentage of children who achieve permanency during their second year in foster care ranges from more than 24 to 63 percent (US DHHS, 2016).

One approach to improving outcomes has been to improve training and support for foster carers. This paper uses focus group and administrative data to assess the extent to which a new approach to foster carer support, called the Quality Parenting Initiative (QPI), improved child welfare outcomes in the places in the United States where it was first introduced. Further, the paper estimates the savings generated by QPI. We construct a logic model of potential outcomes of QPI using information from focus groups of participants. We draw quantitative data on outcomes from the federal Adoption and Foster Care Reporting System (AFCARS) Foster Care Files (see National Data Archive on Child Abuse and Neglect, 2016a, and 2016b). We use internal information on expenditures on QPI and estimate savings using foster care maintenance payment data from AFCARS.

\section{Brief literature review}

For quite a long time, it has been clear that foster carers are key to the provision of safe and stable care for children removed from their families of origin (Brown and Calder, 1999). There are three domains of concern: attachment of foster caregivers with the individual child, knowledge of the specialized work of foster caregiving, and engagement with local child welfare system (Withington, Burton, Lonne, and Eviers, 2016). The need for training and support for foster carers was recognized as early as the 1960s, and systemic approaches first appeared in the 1980s. (See Herbert and Kulkin, 2017, for a brief history.) As understanding of the psychosocial and biological needs of children in foster care improved, researchers have developed programs that are more expansive to enhance the quality of care for foster children. Appendix A summarizes the impact of programs listed by the California EvidenceBased Clearinghouse for Child Welfare (2016) as being highly relevant to child welfare systems and supported by at least 'promising' evidence. The best-known programs are Keeping Foster and Kinship Parents Supported and Trained (KEEP; e.g., Chamberlain et al., 2008; Price et al., 2008), Fostering Individual Assistance program (FAIP; cf. Clark et al., 1996), and various treatment foster care programs (e.g., Farmer et al., 2010). Programs have also been developed and evaluated in other countries (for a recent evaluation, see, Whitehead, 2016). As illustrated by 
the summary of results in Appendix A, despite the difficulties in evaluating such programs (Dickes, Kemmis-Riggs and McAloon, 2017) foster carer training and support programs do seem to improve child behaviors, although the measured effect tends to be small. The measured impact of training programs on the knowledge, skills, self-efficacy, and satisfaction of foster carers has been larger.

Relatively few programs of training and support for foster carers also have been shown to improve foster carer retention, placement stability, and permanency (Piescher \& LaLiberte, 2008). Perhaps this is because the programs omit one of the important domains mentioned above. Most training and support programs aim to enhance understanding of the special behavioral needs and problems of the types of children who are likely to be in care and to promulgate strategies for management them. These are clearly necessary topics for training and support, but foster carers report they are not sufficient. Foster carers also need more information about child welfare systems, including information about relevant policy, procedures, and services available to them and the children in their care (Herbert and Kulkin, 2017). Around the world, foster carers report feeling undervalued and unheard by child welfare systems (McHugh and Pell, 2013).

Nearly all states in the U.S., as well as most jurisdictions in most countries, require foster carers to have pre- or in-service training, and sometimes both. Not all jurisdictions have implemented a training with conclusive scientific evidence of effectiveness. There are two likely reasons. The first is cost. For example, the Annie E. Casey Foundation estimates that the cost of implementation of KEEP is nearly $\$ 100,000$ per local site (personal communication from Kantahyanee Murray and Doreen Chapman of AECF, January 7, 2015). The second reason may be that each place perceives its needs to be unique. Indeed, states do differ widely with respect to child welfare law, policy, and practice (Child Welfare Information Gateway, 2015; Child Trends, 2016).

\section{The Quality Parenting Initiative}

A recent effort to empower foster carers, caseworkers, and supervisors to improve child welfare outcomes within existing child welfare systems is the Quality Parenting Initiative (QPI), which was developed by the Youth Law Center in Washington, D.C. (Youth Law Center, 2016). Jurisdictions and agencies that join QPI are asked to first clarify and articulate high expectations of foster carers and others involved in foster care, then identify and implement changes to make it possible for all participants to live up to those high expectations. QPI aims to improve perceptions of foster care—to 'rebrand' it (Youth Law Center, 2016)—among those involved in it, with the expectation that positive perceptions will spread to the community at large over time. Unlike programs listed in Appendix A, in which every agency or jurisdiction is expected to deliver an identical program, there is no expectation that 
every jurisdiction or agency will articulate expectations identically or that every jurisdiction will choose identical strategies for change.

Because QPI is implemented within existing child welfare systems, it may have lower start-up costs than other foster care improvement programs. Because QPI works on principles of local autonomy rather than using top-down strategies, it also has the potential to identify activities that locally have the greatest impact on outcomes at the lowest costs.

As of 2016, QPI had been implemented in nearly all counties in Florida, 17 counties in California, and a significant area of Nevada, in addition to being implemented in several localities in Pennsylvania and Ohio. The Florida implementation began in 2008: this is the only one that has been in place long enough to evaluate using available data. Florida contracts with private agencies in multicounty regions of the state to provide foster care services. Most regions have a single lead agency. Table 1 shows the years in which the counties, through their agencies, joined QPI. Because counties vary in size, the table also shows the percentage of foster children in Florida that were covered by QPI at the end of the year. By federal fiscal year (FFY) 2013, just over 80 percent of Florida's children lived in a county with a QPI-participating agency, according to our calculations using Census population data.

Table 1

Date on which Florida Counties joined the QPI

\begin{tabular}{|c|c|c|c|c|c|c|c|}
\hline & 2008 & 2009 & 2010 & 2011 & 2012 & 2014 & Not Joined \\
\hline \multirow{20}{*}{$\begin{array}{c}\% \text { of } \\
\text { Children } \\
\text { Covered }\end{array}$} & $14 \%$ & $39 \%$ & $53 \%$ & $69 \%$ & $83 \%$ & $83 \%$ & \\
\hline & BAY & HAFDEI & BREVAFO & BAGA & ALACHA & ESCAMBA & BAOWAPD' \\
\hline & CAHOWN & HGH_ANDS & aTtaus & QAY & BRADFOFD & OKALOOSA & DESOTO \\
\hline & PANKN & ORANGE & FAGA & DADE & O-AROTTE & SANTAROSA & MANATEE \\
\hline & GADSOEN & $\operatorname{Csc} B A \mathrm{~A}$ & HERNADO & MIAMI-DADE' & @urf & WALTON & SAFASOTA \\
\hline & GUF & PALMBEACH" & INDAANRIVER & MONPOE & COUMBRA & & \\
\hline & HILSSOOAOUGH" & PASCO & LAEE & ST.JOHS & DIXIE & & \\
\hline & HOMES & PNELAS & MARION & & DUVAL" & & \\
\hline & JAOKSON & POLK & MARTN & & GLOHRST & & \\
\hline & EAtRSCN & & OKEAHOEI & & GADES & & \\
\hline & LEON & & PUTNAM & & HAMLTON & & \\
\hline & LEसाY & & ST.WCE & & HENDFY & & \\
\hline & SEMINOE & & SUMTER & & LAFAYETIE & & \\
\hline & WAKUUA & & VOLUSA' & & LII & & \\
\hline & WASHINGTON & & & & LEW & & \\
\hline & & & & & MADISON & & \\
\hline & & & & & NASSAU & & \\
\hline & & & & & SUNANWEE & & \\
\hline & & & & & TAMOR & & \\
\hline & & & & & UNION & & \\
\hline
\end{tabular}

Source: Personal communication with Gay Frizzell of the Youth Law Center, May 14, 2015.

* County-specific data are identifiable in AFCARS because county has 1,000 or more children in care. 


\section{Method}

\section{Participants}

To find out about the specific activities and perceived outcomes of QPI, we conducted focus groups over telephone/computer teleconference between April 21 and May 26, 2015. Following IRB approval, recruitment emails were sent to the 63 individuals affiliated with QPI in Florida, California, and Nevada [Appendix B]. All were invited to participate by phone for a one-hour teleconference, and, to reduce potential social demand characteristics and encourage thorough responding, were assured that the teleconferences would not be recorded. Participants included public and private agency staff from several states and many local jurisdictions who have first-hand knowledge of the activities and impressions of the outcomes in the field.

\section{Procedure}

\section{Qualitative development of QPI logic model}

We held follow-up conference calls and one-on-one interviews via telephone and e-mail between June 30 and July 10, 2015. As per our Institutional Review Board protocol, individual participants in the focus groups and interviews are not personally identified. We vetted a summary of the focus group discussion with the participants and refined it into a logic model with their feedback.

\section{Quantitative analysis plans}

No systematic project evaluation of QPI was planned before its implementation. To evaluate QPI, we used administrative data from the 2006-2013 Adoption and Foster Care Reporting System (AFCARS) Foster Care Files (NDACAN, 2016a, 2016b). For each child served in foster care, AFCARS contains information about outcomes, including time to permanency, placement stability, and placement type. It also contains child and case characteristics suitable as control variables, discussed at greater length below. We conducted analyses at two levels: county-level and childlevel. In all analyses, we omitted episodes of less than 15 days in foster care, a benchmark also used in the Child and Family Services Reviews. Because AFCARS includes geocodes only for counties with 1,000 or more children in a data-year, analysis was limited to large counties. Florida counties identified in AFCARS are marked with an asterisk in Table 1.

\section{County-level analyses}

Because we cannot observe several variables that may determine county-level child welfare outcomes, such as the number of caseworkers or turnover of caseworkers in agencies, there is a substantial risk of omitted-variable bias. We therefore used fixed 
effects regression to estimate the impact of QPI on outcomes within each county (cf. Wooldridge, 2010, Chapter 10). 'Treatment' was ' 0 ' for all years if a county agency never participated in QPI and '1' for the years after QPI participation began in a county. To allow for attenuation or amplification of potential benefits of joining QPI, we included the number of years since the county's agency began participating. Controls were: (a) number of children who were served in foster care in the current year, (b) ratio of children who entered foster care to children served in the current year, the share of children served who had disabilities, (c) the proportion of children served who were African American, (d) the proportion who were Hispanic, and (e) the proportion of children served who were under age 6 or over 12 at the start of the fiscal year. Finally, we controlled for the impact of social and economic conditions that could influence the outcomes, specifically (1) years of high heroin use in the county (SAMHSA, 2014) and (2) high unemployment (BLS, 2016) that occurred during the study period, by including the proportion of entries into foster care that were due to (3) parental or (4) child drug abuse and (5) neglect. Omitted categories for reason for removal are alcohol abuse (parental or child), abandonment, caretaker inability to cope, physical abuse, parent death, parent incarceration, relinquishment, and sexual abuse.

\section{Child-level analyses}

Unfortunately, agencies were not randomly assigned to participate or not participate in QPI. Similarly, children were not randomly assigned to agencies participating or not participating in QPI. To address concerns about potential selection bias, we attempted to identify similar children treated by QPI and not treated by QPI via propensity score matching (Leuven $\&$ Sianesi, 2015). The treatment sample was children observed after QPI was implemented while the control sample consisted of children observed before QPI was implemented. We matched on removal reasons, race, age and disability (as in county-level analyses), as well as child gender, percent of the child's lifetime spent in foster care, and type of placement at time of survey (categories include pre-adoptive home, foster family home (relative or non-relative), group home, and institution).

\section{Results}

\section{Qualitative findings: Logic table}

Using data from the focus groups, in conjunction with information from the literature, we constructed a logic table, shown in Figure 1, that links QPI activities (column 2), processes or causal mechanisms (column 3) and expected outcomes (column 4) for children. The figure, which is based on the Cost-Activity-Process-Outcome- 
Analysis (CAPOA) framework formulated by Yates (1996, 1999), also shows the resources (Column 1) and savings (Column 5) that we use below to estimate the ratio of benefits (funds saved) to costs (the value of resources spent to implement QPI).

Fig. 1. Logic of hypothesized resource $\rightarrow$ activity $\rightarrow$ outcome $\rightarrow$ monetary outcome relationships

\begin{tabular}{|c|c|c|c|c|}
\hline Resources & Activities & Processes/Causal Mechanisms & $\begin{array}{l}\text { Outcomes for } \\
\text { Children }\end{array}$ & $\begin{array}{c}\text { Savings from Outcomes for } \\
\text { Children }\end{array}$ \\
\hline $\begin{array}{c}\text { QPI coordinators/advocates } \\
\text { (statewide) }\end{array}$ & $\begin{array}{l}\text { Dissemination of QPI ideal } \\
\text { (rebranding) }\end{array}$ & \begin{tabular}{|c|} 
Enhanced self-efficacy for duties due to \\
acquisition of effective skills and just-in-time \\
info (evident in foster parents, case managers, \\
agencies)
\end{tabular} & $\begin{array}{l}\text { Increased placement } \\
\text { stability }\end{array}$ & $\begin{array}{l}\text { Lower spending on foster care } \\
\text { maintenance payments }\end{array}$ \\
\hline $\begin{array}{c}\text { Staff administrative support } \\
\text { (local agency) }\end{array}$ & $\begin{array}{c}\text { Recruitment, supervision of persons } \\
\text { assisting with QPI dissemination }\end{array}$ & $\begin{array}{c}\begin{array}{c}\text { Increased mutual respect and trust; reciprocal } \\
\text { empowerment (in foster parents, case } \\
\text { managers, agencies) }\end{array} \\
\end{array}$ & $\begin{array}{l}\text { Reduced use of } \\
\text { congregate care }\end{array}$ & $\begin{array}{l}\text { Reduced administrative costs } \\
\text { due to fewer transitions in care }\end{array}$ \\
\hline $\begin{array}{l}\text { Just-in-time training } \\
\text { coordinator }\end{array}$ & Just-in-time training & $\begin{array}{c}\text { Increased pride in being a foster parent, positive } \\
\text { self-regard, professionalism (in foster parents, } \\
\text { case managers, agencies) }\end{array}$ & $\begin{array}{l}\text { Greater likelihood of } \\
\text { permancney }\end{array}$ & $\begin{array}{c}\text { Reduced foster parent } \\
\text { recruitment and training costs } \\
\text { costs per foster child }\end{array}$ \\
\hline \multirow[t]{6}{*}{ Information technologies } & $\begin{array}{c}\begin{array}{c}\text { Operationalization of expectations of } \\
\text { foster parents, case managers, and } \\
\text { supervisors }\end{array} \\
\end{array}$ & $\begin{array}{c}\text { Improved self-management, self-respect, } \\
\text { communication skills, social skills (in foster } \\
\text { children and families of origin) }\end{array}$ & $\begin{array}{l}\text { Reduced time to } \\
\text { permanency }\end{array}$ & \\
\hline & \begin{tabular}{|c|}
$\begin{array}{c}\text { Local selection and development of } \\
\text { most beneficial/least costly policy } \\
\text { changes to support QPI }\end{array}$ \\
\end{tabular} & & & \\
\hline & Lobbying for policy changes & & & \\
\hline & Mutual recognition of importance & & & \\
\hline & Networking among QPI participants & & & \\
\hline & $\begin{array}{l}\text { Mentoring between foster parents } \\
\text { and between foster parents and } \\
\text { families of origin }\end{array}$ & & & \\
\hline
\end{tabular}

\section{Resources}

Facilitating foster care has always been labor-intensive. QPI adds several distinct roles for enthusiastic individuals with different skill sets and different levels of experience with foster care in general, QPI in particular, and with local and state funding and administration. In most states, one to two full-time QPI Coordinator/ Advocates promote, organize, and maintain QPI activities throughout a state or large area within a state. Each local agency needs administrative support from staff who are knowledgeable about QPI. A coordinator familiar with foster care, QPI, and information technology provides, adapts, and updates just-in-time training for solving specific foster care challenges. This training is delivered via short, problem-focused videos on the QPI website that individual foster carers can access immediately on-demand via information technologies such as computers, tablets, and smartphones with high-speed internet connections.

\section{Activities}

Focus-group participants expressed much enthusiasm for QPI, but their descriptions of many of the activities that they associate with QPI were amorphous, not operational. The most-discussed QPI activity was the dissemination by paid coordinator-advocates and by foster carers of the idea that foster caregiving ought to be quality caregiving. Participants noted that dissemination required recruitment and supervision of QPI participants. 
Another much-discussed QPI activity was just-in-time web-based training. Jurisdictions that implement QPI also contract with Florida's Center for Child Welfare to produce online video libraries for training in basic, advanced, and trauma-informed parenting skills (e.g., Salas et al., 2015) and for the dissemination of locally relevant information on child welfare and family court systems to foster carers. Web-enhanced training can improve foster carer recall by up to 50 percent (Delaney et al., 2012). Just-in-time trainings are available to foster carers continuously, so that their knowledge could be regularly refreshed. Moreover, foster carers are encouraged to request new trainings as problems arise.

Participants decided that three specific changes in child welfare policy and procedure would be the most beneficial. In Florida, lobbying efforts for the following were successful: (a) formative, positive evaluation of foster carers by case managers and vice versa, to formalize the high expectations for foster carers and the child welfare system; (b) standardization of home studies, emphasizing quality caregiving; and (c) modified regulations and enhanced funding that allow children in foster placements to be integrated more thoroughly into foster families (for example, new regulations make it easier for foster children to accompany their foster families on vacation).

Focus group participants believed that as a result of QPI, foster carers and caseworkers more frequently expressed appreciation of each other's' efforts, and Florida QPI participants remarked that appreciation was now made public there through an awards system. Frequently discussed was the extensive networking of QPI participants within states and the transfer of information across states through shared contacts such as the Youth Law Center and Florida's Center for Child Welfare. Finally, it was believed that QPI resulted in an increase in the mentoring of new foster carers by more experienced ones, as well as an increase in the mentoring of families of origin by foster carers.

\section{Processes}

Focus group participants identified four processes, i.e., causal mechanisms mediating activities and outcomes, that they believe to be at work:

- Enhanced self-efficacy for duties due to acquisition of effective skills and justin-time information (expected to be evident in foster carers, case managers, agencies). Self-efficacy refers to the expectation that one can accomplish specific tasks that result in specific goals (Dominick et al., 2015).

- Increased pride in being a foster carer, positive self-regard, professionalism (expected to be evident in foster carers, case managers, agencies).

- Increased mutual respect and trust; reciprocal empowerment (expected to be evident in foster carers, case managers, agencies).

- Improved self-respect, enhanced trust in adults, and more effective skills for self-management, communication (Gries, 1986), social interaction (Suzuki \& 
Tomoda, 2015) (expected to be evident in foster children and in their families of origin).

\section{Outcomes}

QPI focus group participants indicated that an intermediate outcome of QPI activities was an increase in the number of foster carer homes, which they viewed as resulting from a combination of increased recruitment of new foster carers and retention of existing ones. More and better-trained foster carers, they believed, led to improvements in four key short-term outcomes for children: fewer placement disruptions, fewer placements in congregate care, a higher probability of permanency, and less time in care. They expressed hope that these improved short-term outcomes would lead to better medium- and long-term outcomes for children including better educational attainment and reduced risky behaviors.

\section{Quantitative findings: Outcomes}

Of the child welfare outcomes found to be important in the qualitative analysis, AFCARS contains data on placement disruption, use of congregate care, the probability of permanency, and time to permanency. We considered the following dependent variables: the number of placements during most recent episode in foster care, the probability of being placed in congregate care upon entry into foster care, whether the child was adopted during the year (if the child was waiting to be adopted), days from removal to adoption (if the child was adopted), and the number of days from removal to reunification (if the child was reunified with his or her family of origin). QPI is statistically significantly associated only with improvements in time to reunification for children who were reunified with their families of origin; therefore, the tables below focus on this outcome. Results for other outcomes are available in Appendix C (for county-level analyses) and D (for child-level analyses). All quantative analsyis was conducted in Stata.

\section{County-level results}

There are 14 counties with geocodes in AFCARS. A small number of counties did not meet the 1,000-observation threshold for geocoding in every year, so there are 86 observations over the 2006-2013 FFYs. Descriptive statistics of the county-level attributes of these observations are shown in Table 2. The typical reunification in the typical county was achieved after the child had been in care about 314 days. The typical county's median days to reunification is a slightly lower 254 days. Average days to adoption is 938; median is 799 .

Table 3 shows the main results, which were obtained by specifying the fe option of the xtreg command in Stata. For children who were reunified, the average number of days in foster care increased by 3.5 weeks per year throughout Florida over the 
2006-2013 period, as indicated by the positive trend in the regressions reported in Table 3. There was no immediate effect of joining QPI on time to reunification. However, with each additional year of participation in QPI, counties reduced mean days to reunification by nearly two weeks relative to the trend increase. In other words, time to reunification increased less quickly in participating counties. Median days to reunification were not different in participating and non-participating counties, implying that the main effect of QPI participation was on permanency for children who have been in care for a relatively long time. We also note that there was substantial heterogeneity of impact between counties. Hillsborough, Pinellas, and Miami-Dade counties are outliers in the good sense: these counties have lower mean time to reunification after joining QPI than they had before.

Table 2

Descriptive statistics

\begin{tabular}{lcc}
\hline & Mean & Standard Deviation \\
\hline Dependent Variables & & \\
\hline Mean Days to Reunification & 313.88 & 53.72 \\
Median Days to Reunification & 253.98 & 50.97 \\
Mean Days to Adoption & 938.53 & 181.52 \\
Median Days to Adoption & 799.46 & 166.67 \\
\hline Independent Variables & & \\
\hline Children Served & & \\
Entered/Served & 2102.74 & 934.53 \\
Years of QPI Participation & 0.40 & 0.05 \\
\% Removed for Parent Drug Abuse & 0.90 & 1.37 \\
\% Removed for Child Drug Abuse & 0.40 & 0.11 \\
\% Removed for Neglect & 0.02 & 0.01 \\
\% Removed for Inadequate Housing & 0.24 & 0.12 \\
\% Black/African American & 0.14 & 0.04 \\
\% Hispanic & 0.43 & 0.15 \\
\% Younger than 6 & 0.13 & 0.08 \\
\% Older than 12 & 0.49 & 0.04 \\
\% with Intellectual Disability & 0.23 & 0.04 \\
\% with Mental Health Diagnosis & 0.01 & 0.01 \\
\% with Other Condition & 0.05 & 0.03 \\
\hline
\end{tabular}

Source: Authors' calculations using AFCARS Foster Care files. Limited to children served at least 15 days in counties with 1,000 or more observations in a FFY. 
Table 3

Effect of QPI on time to permanency, fixed effects

\begin{tabular}{lcccc}
\hline & $\begin{array}{c}(1) \\
\text { Average } \\
\text { Days if } \\
\text { reunified }\end{array}$ & $\begin{array}{c}\text { Median } \\
\text { Days if } \\
\text { adopted }\end{array}$ & $\begin{array}{c}(3) \\
\text { Average } \\
\text { Days if } \\
\text { reunified }\end{array}$ & $\begin{array}{c}\text { Median } \\
\text { Days if } \\
\text { adopted }\end{array}$ \\
\hline Federal FFY & $24.124^{* * *}$ & $20.101^{* * *}$ & $-32.280^{*}$ & -21.166 \\
After Joining QPI & $(6.086)$ & $(5.804)$ & $(18.283)$ & $(19.028)$ \\
& -9.601 & -18.646 & 53.323 & 24.112 \\
Years QPI in Place & $(15.559)$ & $(14.838)$ & $(46.739)$ & $(48.644)$ \\
& $-12.922^{* *}$ & -3.558 & -1.852 & -13.774 \\
\hline Observations & $(6.254)$ & $(5.964)$ & $(18.788)$ & $(19.554)$ \\
$R^{2}$ & 86 & 86 & 86 & 86 \\
Number of Counties & 14 & 0.588 & 0.586 & 0.530 \\
\hline
\end{tabular}

$* p<.10 . * * p<.05 . * * * x<.01$.

Source: Authors' calculations using AFCARS Foster Care files. Standard errors in parentheses. Estimated using fixed effects to reduce omitted variable bias. Controls included are number of children served, ratio of children entered to children served, entries due to parent or child drug abuse, entries due to neglect, child disabilities, and age. Includes counties with 1,000 or more children served during a FFY.

\section{Child-level results}

After excluding observations without geocodes and observations with missing data, there were 33,735 observations of reunified children and 16,277 observations of adopted children used in the child-level analyses. All models utilized nearest neighbor matching in Stata and included a constant and a control for county. First stage PSM results are in Appendix D, Table Dl.

The child-level results are similar to the county-level results. Table 4 shows the difference in mean days to permanency for the treated and untreated groups, which is the average treatment effect on the treated ('ATT'). Among children who were similar ('matched observations'), those who were reunified after implementation achieved permanency nearly ten days sooner on average. There was no significant effect of QPI on time to permanency if the child was adopted. Fixed-effects models suggest that county-level differences influence the effect of QPI on time to permanency. Again, there was significant heterogeneity. When we performed the analysis at the county level (not shown, available upon request), Miami-Dade and Pinellas counties had statistically significant reductions in both time to reunification and time to adoption after implementing QPI. Hilsborough county had a statistically significant reduction in time to reunification of 49 days. 
Table 4

Effect of QPI on time to permanency, PSM

(1)

Average Days

if Reunified
(2)

Average Days

if Adopted

Treated-Untreated

ATT

$-9.992 * *$

(4.267)

33,735

0.036
$-12.760$

(13.838)

16,277

0.037

R-squared

$* p<.10 . * * p<.05 . * * *<<.01$.

Source: Authors' calculations using AFCARS Foster Care files. Standard errors in parentheses. Estimated using propensity score matching. Controls as in table 3. Includes counties with 1,000 or more children served during a FFY. First stage results appear in Appendix D (Table D1).

\section{Quantitative findings: Savings to expenditures ratio}

If children are reunified more quickly, the aggregate amount of foster care maintenance payments made by state, some of which are partially reimbursed by the federal government, will be lower. To estimate the potential savings from QPI in each year, it is first necessary to estimate typical annual and daily maintenance payments. AFCARS contains maintenance payment data. Specifically, it records the amount of the last month's foster care maintenance payment paid on behalf of each child served in foster care. Lump sum payments under contracts to operators of group homes or institutions are not included, so the AFCARS-reported payments are the lower bound of costs per child in those placement settings.

Figure 2 shows the average annual foster care maintenance payments made per child in Florida foster care by placement setting. Until FFY 2012, maintenance payments made on behalf of children in group homes ( $n=2,151$ annually on average) and institutions $(n=2,292)$ were about three times larger than payments made on behalf of children in family settings. Payments made on behalf of children in preadoptive homes $(n=3,550)$, relative foster homes $(n=17,977)$ and nonrelative foster homes $(n=12,409)$ did not differ significantly. The last two years of data showed a dramatic increase in foster care maintenance payments in family settings ( $n=$ 28,995 annually), although congregate care $(n=3,717)$ remained about $\$ 10,000$ more expensive per child. The increase in payments for children in family settings appeared to reflect a change in rates for specialized care because the basic foster 
care maintenance rate ranged from about $\$ 4,800$ per year for children five and younger to about $\$ 6,000$ per year for teens (for current rates, see FDCF, 2016). As discussed more below, most children who were reunified were placed in relative or non-relative foster homes. As a result, the increase in maintenance rates made the potential savings from quicker reunification substantially larger beginning in 2012.

Fig. 2. Annual foster care maintenance payment by placement setting, Florida

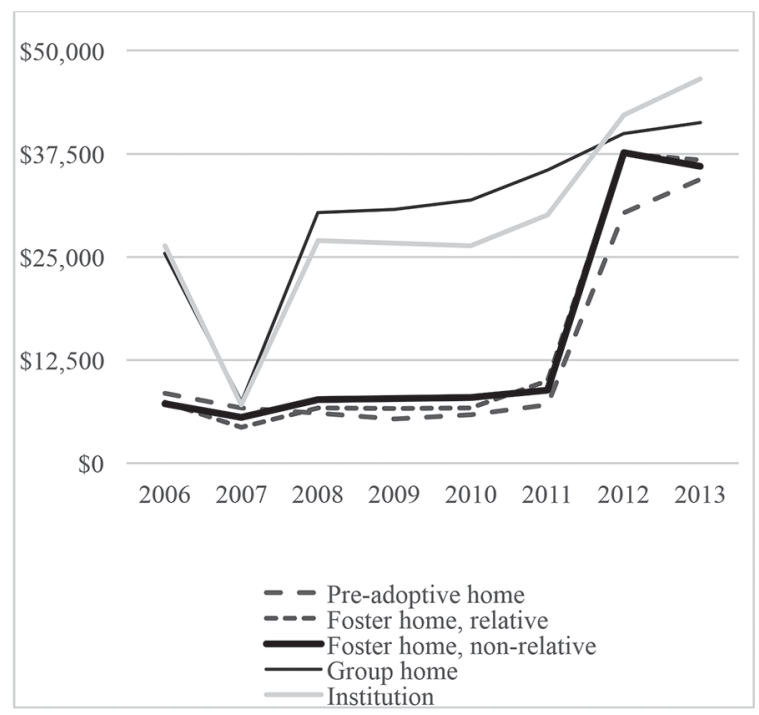

Source: Authors' calculations using AFCARS Foster Care files. See text for details.

Table 5 shows expected savings from shorter time to reunification. The top panel shows the reduction in the aggregate number of days children spent in care, by placement setting, which was calculated as reduced days in care per child (from the fixed effects estimate in Table 3) times the number of children reunified by setting in counties with QPI (as recorded in AFCARS). The figures in the top panel are multiplied by the daily payment by setting during each year to arrive at the total savings shown in the bottom panel. Savings increased from about $\$ 250,000$ in 2009, 95\% CI [ $\$ 124,970, \$ 363,549$ ], to nearly $\$ 18$ million in $2013,95 \%$ CI [ $\$ 9.2$ million, $\$ 26.8$ million], because of (a) expansion of QPI, (b) amplification of the effect of QPI over time, and (c) increase in foster care maintenance payments per child. 
Table 5

Savings associated with QPI in Florida

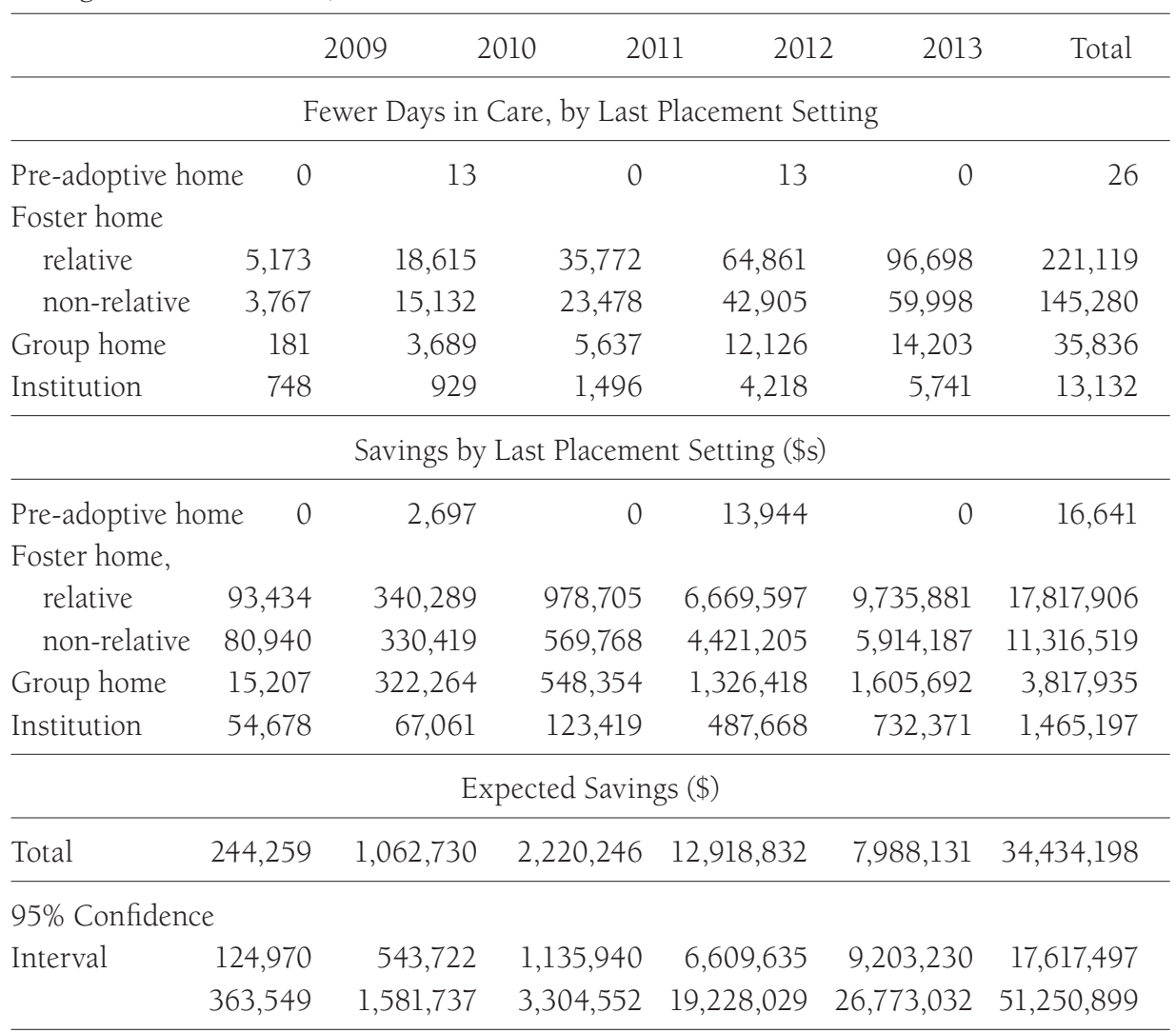

Source: Authors' calculations using AFCARS Foster Care files. See text for details, including information on of the number of valid observations.

\section{Cost of QPI}

Only incomplete data were available for the cost of implementing QPI in Florida because much was rolled into the state's large contract with Florida's Center for Child Welfare (personal communication with Don Policella, September 4, 2015). Data were more complete for California's 2013 QPI implementation in California (Table 6). We learned from our focus groups that each state with QPI-participating areas allocates one to two Full Time Equivalents (FTEs) of trained social workers to coordination and state action ('resources' in Figure 1). Possibly because of its large geographical area, California reported having two state-wide coordinators. In each of the 17 participating counties in California, the QPI 'lead' spent several days each month on QPI-specific activities. However, because promulgating QPI ideals affects a large number of other activities, focus group participants were unable to 
accurately estimate their time commitments or the commitments of the colleagues and foster carers. Focus group participants were understandably not eager to tell us about the nonQPI activities they set aside in order to work on QPI. Table 6 uses the rough estimate of one day per week at each agency per region participating. Again, our summary was vetted with the focus group participants. We value the time of QPI coordinators, advocates, and leads at the annual mean wage of social workers in California in 2013 (BLS, 2014).

Table 6

Expenditures on QPI in California, 2013

\begin{tabular}{lrcr}
\hline & Effort & Cost per FTE (\$) & Total (\$) \\
\hline 2 State Coordinators/Advocates & $100 \%$ & 49,820 & 99,640 \\
Staff effort per county for 17 sites & $14 \%$ & 49,820 & 120,991 \\
Just-In-Time Training & & & \\
$\quad$ Coordinator & $50 \%$ & 49,820 & 24,910 \\
$\quad$ Video Tech. & $50 \%$ & 50,600 & 25,300 \\
$\quad$ Other Direct Costs & & & 88,338 \\
\hline
\end{tabular}

Total for 17 Participating Counties

359,179

Cost per County

21,128

Sources: Average annual wages for Child and Family Social workers and Audio \& Video Equipment Technicians, BLS (2014). JIT FTE and Other Direct Costs from personal communication with Don Policello, September 8, 2015.

We also obtained information on the resources used to produce the just-in-time training for California, which is done by contract with Florida's Center for Child Welfare. The contract for California's just-in-time training budgeted 0.5 FTE for a coordinator based in California and knowledgeable in state child welfare issues, and a 0.5 FTE for local technical support for filming. Other direct and indirect costs were estimated at $\$ 88,338$. (Personal communication with Don Policella, September $8,2015)$. The total estimated expenditures on QPI California in 2013 are $\$ 359,179$, or $\$ 21,128$ per participating county.

\section{Estimated savings-to-expenditures ratio}

If average expenditures are constant, the cost of implementing QPI throughout the 58 counties of California would be about $\$ 1.23$ million. This is likely an overestimate because it is reasonable to expect that there are economies of scale in QPI implementation. For example, providing just-in-time training to all of California may require a full-time coordinator and a full-time technician, but it is unlikely to require much more than that.

Assume that QPI in California has the same impact as seen in Florida, with time 
in care about 13 days shorter for each child reunified. This would result in almost 121,000 fewer days in care overall. The majority of children in California foster care were reunified from nonrelative foster family care, but a significant proportion were reunified from kinship care. Only about five percent of reunifications were for children in group homes or institutions, and only a handful of older teens in supervised independent living situations returned home.

Figure 3 shows the annual amount of maintenance payments in FFY 2013 by placement setting in California, calculated from AFCARS in the same way as the multi-year estimate for Florida shown in Figure 2. Maintenance payments to kinship caregivers average less than 50 percent of payments to non-kin foster carers. While independent living placements cost slightly less than non-kin foster placements, congregate care in California is more than five times more expensive than family foster care.

Fig. 3. Annual Foster Care Maintenance Payment by Placement Setting, California 2013. Source: Authors' calculations using AFCARS Foster Care files. See text for details.

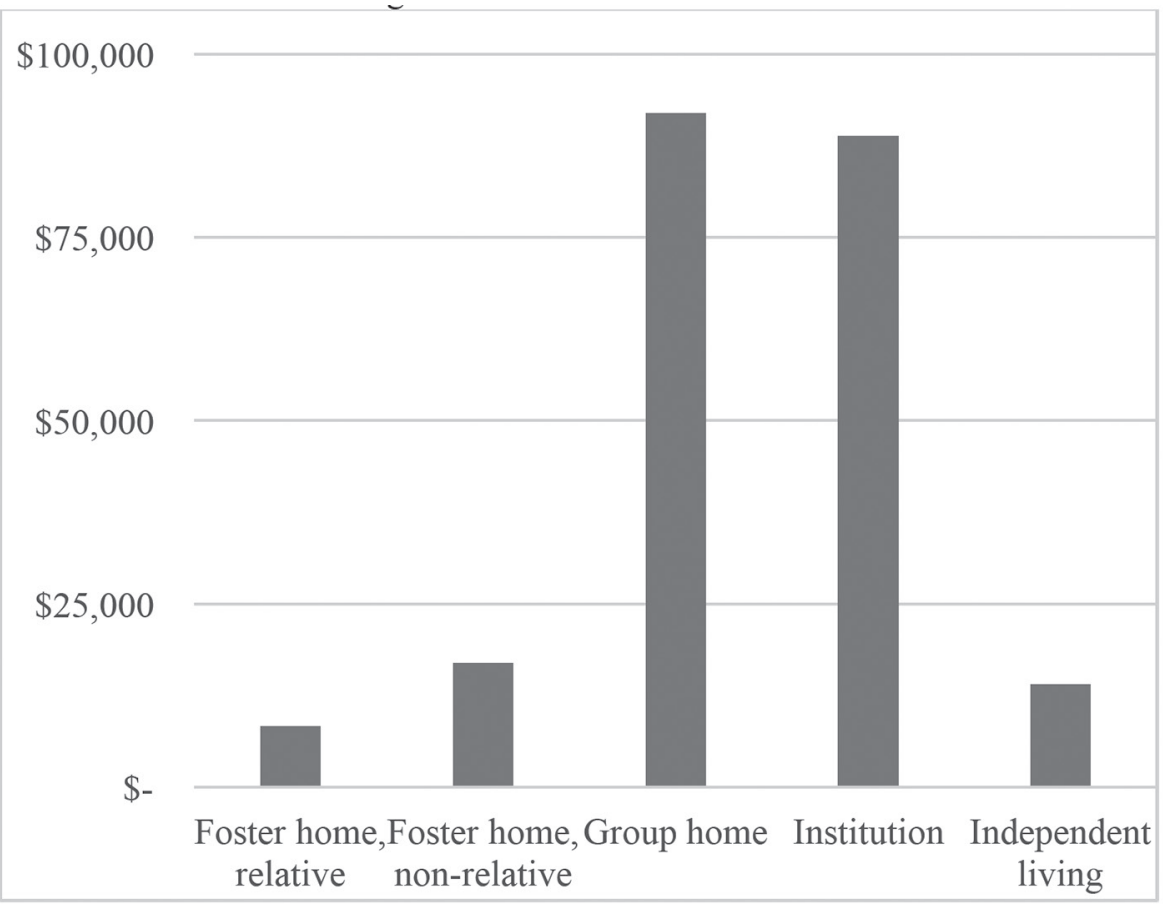

The potential savings from a statewide implementation of QPI in California are shown in Table 7. California might have been able to save $\$ 7.6$ million by shaving as little as 13 days off the stays of children who are reunified. Since congregate care was so expensive in California, reducing the stays of these children had an outsize effect on savings. The implied ratio of savings to expenditures is $6.24,95 \%$ CI. [3.19, 9.29]. 
Table 7

Savings Associated with QPI in California

\begin{tabular}{|c|c|c|c|}
\hline & 2013 & \multicolumn{2}{|c|}{ 95\% Confidence Interval } \\
\hline \multicolumn{4}{|c|}{ Fewer Days in Care, by Last Placement Setting } \\
\hline Foster home, relative & 48,839 & 24,988 & 72,691 \\
\hline Foster home, non-relative & 66,732 & 34,142 & 99,322 \\
\hline Group home & 7,043 & 3,604 & 10,483 \\
\hline Institution & 6,837 & 3,498 & 10,176 \\
\hline Independent living & 90 & 46 & 134 \\
\hline Total & 129,542 & 66,277 & 192,806 \\
\hline \multicolumn{4}{|c|}{ Savings by Last Placement Setting ( $\$$ s) } \\
\hline Foster home, relative & $1,108,367$ & 567,071 & $1,649,662$ \\
\hline Foster home, non-relative & $3,095,298$ & $1,583,641$ & $4,606,955$ \\
\hline Group home & $1,774,282$ & 907,772 & $2,640,791$ \\
\hline Institution & $1,664,781$ & 851,748 & $2,477,813$ \\
\hline Independent living & 3,465 & 1,773 & 5,158 \\
\hline Total Expected Savings & $7,646,192$ & $3,912,005$ & $11,380,379$ \\
\hline Savings/Expenditures & 6.24 & 3.19 & 9.29 \\
\hline
\end{tabular}

Source: Authors' calculations using AFCARS Foster Care files. See text for details.

\section{Discussion}

The savings-to-expenditures ratio found for QPI is similar to what has been reported for a variety of other human services, providing some assurance of its validity. For substance abuse treatment in similarly quasi-experimental studies, societal costsavings benefits in reduced use of health and other services, and earnings increments, outpace treatment costs by as much as 7:1 (Ettner et al., 2006; see also Daley et al., 2000), with a low of 3:1 (French et al., 2002). Outpatient psychotherapies of several types also return in reduced health care costs more than twice their own cost. As early as 1975, Cummings found that one to four sessions of psychotherapy returned an average 2.59 dollars for every dollar spent for therapy. Cavanaugh (1978) reported that psychotherapy reduced hospitalization for physical health problems from a mean 111 days to a mean 53 days in a four-year study: a 52\% reduction in high-cost inpatient services. Jones and Vischi (1979) found that visits for x-rays, diagnoses, and recovery time from surgery decreased significantly after psychotherapy. Comprehensive longitudinal studies suggest that a mean of less than 
9 sessions of therapy reduces medical services by 75\% (Yates, 1981). More recent studies produce similar findings, e.g., Markowitz (2015).

The number of child welfare outcomes that were found to be associated with the implementation of QPI was more limited than the number of outcomes associated with other participation in programs such as were more limited than the foster carer training program Keeping Foster and Kinship Parents Supported and Trained (KEEP). Whereas KEEP was not shown to reduce time to reunification, it was shown to increase the probability of reunification (Price et al., 2008). Moreover, KEEP broke the link between past disruptions and future disruptions, including reducing the probability that a child would be moved to a more restrictive setting. It is possible, of course, that the less robust effects of QPI are an artifact of the rough nature of the data on the timing of implementation of QPI and the necessity of using administrative data rather than data collected specifically for the purpose of evaluation of QPI.

\section{Limitations}

This study is the first to consider whether QPI has a measurable impact on child welfare outcomes. However, the brief history and limited geographical extent of QPI, the constraints of available data, and the amorphous nature of QPI present challenges for replicating and generalizing our findings.

\section{Brief history and limited geography of QPI}

Because QPI is such a new approach to improving child welfare outcomes, the time frame of this study was limited to a small number of years and the scope of the study is limited to the single state of Florida. We know little about the history of QPI in Florida. Our data on the participation of agencies in Florida come from the email archives of a single QPI advocate and are available only at the level of the calendar year. The resulting measurement error in our variables representing participation - that is, the fact that counties that began participating in QPI in January and December of a calendar year have the same values for the year of implementation of QPI and the length of participation in QPI in our data - probably reduces the likelihood of finding any statistically significant effects of QPI. It may also exert downward bias in the size of the effects we do find. Moreover, because Florida's system of contracting with private regional agencies is somewhat unique (cf. Albowicz, 2004, for a description), it is difficult to predict with great confidence that QPI will have the same effects in states and localities where the child welfare system is organized differently. The statistically significant and meaningful effects of QPI on time to reunification found here are hopeful signs that future studies of QPI will reveal even stronger positive impact, but further study is warranted.

We also do not know why agencies joined QPI when they did. This makes it difficult to discern whether there are unobserved and confounding factors that 
influenced the outcomes. Though our empirical strategy aims to minimize omitted variable bias by considering changes over time within counties, more consideration needs to be given to the origin of the strong upward trend in time to reunification in most places in Florida.

\section{Limitations of AFCARS data}

Though the quality of AFCARS data has improved significantly since the system became mandatory in the late 1990s, there are still many observations that contain invalid or missing values of variables. Perhaps most problematic in the data for FFYs 2006-2013 used here are missing or invalid values for key dates, such as entry dates and dates of changes in placement settings. Florida's data have a particularly large number of missing dates, so that the measures of placement stability are based on less than half of the records. Fortunately, supplemental univariate logistic regression analyses did not reveal systematic predictors of missing data, so we have little reason to suspect bias in the results presented here.

\section{Limitations of data on cost}

Recall error and personnel turnover limit the ability of the researcher to measure time use or costs of personnel or volunteers retrospectively in general. In this study the opportunity cost of the time that QPI requires of other child welfare professionals and volunteers was not considered, because our contacts did not have sufficient information for us to feel comfortable estimating these costs. Our savings-toexpenditure ratios are therefore rough and conjectural. To obtain a true measure of time use on QPI will require significant cooperation with state and local agencies.

\section{Nature of QPI}

It is a challenge to measure the impact of a set of ideals, as opposed to a carefully formulated and replicable program. Moreover, because QPI emphasizes local autonomy, each state or site where it is implemented could decide to engage in different activities and aim to achieve different outcomes. This obviously limits the generalizability of a study of its benefits or costs. We note, however, that the activities of the early participants (described above) were similar. Moreover, leaders of QPI at the Youth Law Center, in cooperation with Florida's Center for Child Welfare at the University of South Florida, have worked to establish regular channels of communication and resource-sharing among QPI participants, which may tend to make future implementations of QPI both more similar and less expensive than the first ones.

On the other hand, the fact that QPI has the potential to identify at a local level the activities that will generate the greatest benefits for the lowest costs makes it the most promising kind of program to study in our federal system of child welfare. 


\section{Future avenues for research}

We have demonstrated that QPI as currently implemented in a major state is correlated with outcomes that can enhance children's lives while saving taxpayer dollars. However, limitations of the available data, the amorphous nature of QPI, and its relatively brief history limited our ability to conduct a complete and definitive cost-benefit analysis.

One way to better evaluate the cost-benefit of QPI is to plan the systematic collection of data on the same set of benefits, and the same set of costs, for two or more simultaneous implementations of QPI in randomly chosen areas (e.g., counties) in each of several states. For better generalizability, we would involve one state that currently has long times to reunification of children with their natural families, and another state that has more typical reunification times. By directing similar amounts of resources in a systematic manner to dissemination of QPI in the selected areas, and by monitoring the fidelity with which QPI activities are implemented in each- and in the comparison areas of each state in recognition of the possibility of contagion of QI activities beyond target areas - we could measure the possible reduction in time to reunification, resulting savings, the hypothesized improvements in other outcomes, and any additional costs of QPI over the usual foster caregiving approaches continuing to be carried out in comparison areas. So that comparison counties could also benefit from QPI, and of course contingent on further demonstration of QPI advantages, we could randomly assign different jurisdictions (e.g., counties within states) to one of three groups: (1) immediate implementation of QPI, (2) a one-year delay of implementation of QPI, or (3) a three-year delay of implementation QPI. This randomized lagged multiple baseline design also could aid recruitment and commitment of different areas of different states, all of which would eventually receive (and hopefully benefit from) QPI.

We suggest collecting monthly data on outcomes, time use, and financial resources expended on activities related to fostering from each jurisdiction. Appendix B gives a more detailed account of the framework and data required.

Data also need to be collected on short- and long-term outcomes of QPI for the children. We propose collecting these data for samples of foster children and foster carers who have and have not yet participated in QPI. An optimal design would allow for comparison with other longitudinal studies of children who have been in foster care, such as the long term foster care sample that is part of the National Survey of Child and Adolescent Well-Being and the Midwest Study of the Adult Functioning of Former Foster Youth. Statistically comparing these data on resources, activities, processes, and both nonmonetary and monetary outcomes, and quantifying the relationships between each, would allow us to empirically test the model we have developed. 


\section{References}

Albowicz, K. (2004) Florida's experiment with privatizing child welfare services, The American Federation of State County and Municipal Employees (AFSCME), AFL-CIO [Accessed 1 September 2015 at http://www.afscme.org/news-publications/publications/privatization/ pdf/flchild.pdf]

Bell, T. and Romano, E. (2017). Permanency and safety among children in foster family and kinship care: A scoping review. Trauma, Violence, \& Abuse, 18,3, 268-286.

Bureau of Labor Statistics (2014) May 2013 State Occupational Employment and Wage Estimates California [Accessed 29 July 2016 at http://www.bls.gov/oes/2013/may/oes_ ca.htm\#21-0000]

Brown, J., \& Calder, P. (1999) Concept mapping the needs of foster parents. Child Welfare, $76,6,729-746$

Bureau of Labor Statistics (2016) Local Area Unemployment Statistics, Unemployment rates by State [Accessed 25 July 2016 at http://data.bls.gov/map/MapToolServlet?survey=la\&ma $\mathrm{p}=$ state\&seasonal $=\mathrm{u}]$

California Evidence-Based Clearinghouse for Child Welfare (2016) Programs [Accessed 21 July 2016 at http://www.cebc4cw.org/ http://www.cebc4cw.org/search/]

Cavanaugh, as cited in C. Holden (1978), Senators hear case for psychotherapy. Science, 201, 794-795.

Chamberlain, P., Price, J., Reid, J., \& Landsverk, J. (2008) Cascading implementation of a foster and kinship parent intervention. Child Welfare, 87,5, 27.

Child Trends (2016) State Child Welfare Policy Database [Accessed 31 December 2017 at http:// www.childwelfarepolicy.org/]

Child Welfare Information Gateway (2015) Links to State and Tribal Child Welfare Law and Policy. [Accessed 29 July 2016 https://www.childwelfare.gov/topics/systemwide/lawspolicies/statutes/resources/.

Clark, H, B., Boyd, C. S. A., \& Eamon, M. K. (2007) Self-perception of fulfilling the foster caregiver role measure. doi: 10.1037/t23467-000.

Clark, H. B., Lee, B., Prange, M. E., \& McDonald, B. A. (1996) Children lost within the foster care system: Can wraparound service strategies improve placement outcomes? Journal of Child and Family Studies, 5,1, 39-54.

Cummings, N. A. (1977) Prolonged (ideal) versus short-term (realistic) psychotherapy. Professional Psychology, 8, 491-501.

Daley, M., Argeriou, M., McCarty, D., Callahan, J. J., Shepard, D. S. \& Williams, C. N. (2000) The costs of crime and the benefits of substance abuse treatment for pregnant women. Journal of Substance Abuse Treatment, 19, 4, 445-458

Delaney, R., Nelson, C., Pacifici, C., White, L., \& Smalley, B. K. (2012). Web-enhanced preservice training for prospective resource parents: A randomized trial of effectiveness and user satisfaction. Journal of Social Service Research, 38, 4, 503-514.

DeVooght, K. \& Blazey, D. (2013). Family Foster Care Reimbursement Rates in the U.S. Accessed 31 December 2017 at http://childtrends.org/wp-content/uploads/2013/04/Foster-Care- 
Payment-Rate-Report.pdf]

Dickes, A., Kemmis-Riggs, J. and McAloon, J. (2017) Methodological challenges to the evaluation of interventions for foster/kinship carers and children: A systematic review. Clinical child and family psychology review [Accessed 10 January 2017 at https://link.springer. com/article/10.1007/s10567-017-0248-z]

Dominick, G., Saunders, R., Friedman, D., Hussey, J.\& Watkins, K. W. (2015) Factors associated with provision of instrumental social support for physical activity in a foster parent population. Children and Youth Services Review, 52, May, 1-7. doi: 10.1016/j. childyouth.2015.02.005.

Ettner, S. L., Huang, D., Evans, E., Ash, D. R., Hardy, M., Jourabchi, M., \& Hser, Yih-Ing (2006) Benefit-cost in the California Treatment Outcome Project: Does substance abuse treatment 'pay for itself'? Health Services Research, 41, 1, 192-213.

French, M. T., McCollister, K. E., Cacciola, J., Durell, J/, \& Stephens, R. L. (2002) Benefit-cost analysis of addiction treatment in Arkansas: Specialty and standard residential programs for pregnant and parenting women. Substance Abuse, 23, 1, 31-51.

Gries, L. \& Farmer, E. (1986) The use of multiple goals in the treatment of foster children with emotional disorders. Professional Psychology: Research and Practice, 17, 5, 381-390. doi:10.1037/0735-7028.17.5.381.

Farmer, E. M., Burns, B. J., Wagner, H. R., Murray, M., \& Southerland, D. G. (2010) Enhancing 'usual practice' treatment foster care: findings from a randomized trial on improving youths' outcomes. Psychiatric Services, 61, 6, 555-561.

Florida Department of Children and Families (FDCF) (2016) My Future, My Choice - for Foster Parents [Accessed 28 July 2016 at http://www.myflfamilies.com/service-programs/ independent-living/myfuturemychoice-fp]

Hebert, C.G. and Kulkin, H., (2017) An investigation of foster parent training needs. Child \& Family Social Work. DOI: 10.1111/cfs.12413

Jones, K., \& Vischi, T. (1979) Impact of alcohol, drug abuse, and mental health treatment on medical care utilization. Medical Care, Special Supplement, December.

Leuven, E., \& Sianesi, B. (2015) PSMATCH2: Stata module to perform full Mahalanobis and propensity score matching, common support graphing, and covariate imbalance testing. [Accessed 9 August 2016 at https://ideas.repec.org/c/boc/bocode/s432001.html]

Markowitz, J. C. (2015) Is psychotherapy for personality disorders worth it? Journal of Clinical Psychiatry, 76, 11, 1472-1473.

McHugh, M., \& Pell, A. (2013) Reforming the foster care system in Australia. Sydney: UNSW: Social Policy Research Centre.

National Data Archive on Child Abuse and Neglect (2016a) Adoption and Foster Care Analysis and Reporting System (AFCARS) Annual File User's Guide for Fiscal Years 2000 to Present [Accessed 22 July 2016 at http://www.ndacan.cornell.edu/datasets/dataset-details. cfm?ID=187]

National Data Archive on Child Abuse and Neglect (2016b) Adoption and Foster Care Analysis and Reporting System (AFCARS) Foster Care File Code Book [Accessed 22 July 2016 at http:// www.ndacan.cornell.edu/datasets/dataset-details.cfm?ID=187] 
Piescher, K. N., \& LaLiberte, T. (2008) Evidence-based practice in foster parent training and support: Implications for treatment foster care providers. Center for Advanced Studies in Child Welfare, University of Minnesota School of Social Work. [Accessed 9 November 2010 at http://cascw.umn.edu/portfolio-items/ebp-in-foster-parent-training-tfc-pub/]

Price, J. M., Chamberlain, P., Landsverk, J., Reid, J. B., Leve, L. D., \& Laurent, H. (2008) Effects of a foster parent training intervention on placement changes of children in foster care. Child Maltreatment, 13, 1, 64-75.

Salas, M. D., García-Martín, M. Á., Fuentes, M. J., \& Bernedo, I/ M. (2015) Children's emotional and behavioral problems in the foster family context. Journal of Child and Family Studies, 24, 5, 1373-1383. doi: 10.1007/s10826-014-9944-1.

SAMHSA (2014) Population Data/NSDUH by State and Substate Areas [Accessed 25 July 2016 at http://www.samhsa.gov/data/reports-by-geography?tid=627\&map=1]

Suzuki, H., \& Tomoda, A. (2015) Roles of attachment and self-esteem: Impact of early life stress on depressive symptoms among Japanese institutionalized children. BioMed Central: Psychiatry, 15, Feb 5, Article 8.

Tarren-Sweeney, M. (2013) Assessment Checklist for Adolescents (ACA). doi: 10.1037/t22649000 .

US DHHS (2016) Administration for Children and Families, Children's Bureau, Child and Family Services Reviews [Accessed 31 Dewcember 2017 at http://www.acf.hhs.gov/programs/cb/ monitoring/child-family-services-reviews)]

Withington, T., Burton, J., Lonne, B. and Eviers, A. (2016) Carer perspectives of factors affecting placement trajectories of children in out-of-home care. Children and Youth Services Review, 65, June, 42-50. https://doi.org/10.1016/j.childyouth.2016.03.006

Whitehead, L.M. (2016) Exploring foster carers' perceptions of the long-term effectiveness of the Fostering Changes training programme. Master's thesis, University of Canterbury, New Zealand.

Wooldridge, Jeffrey M. (2010) Econometric Analysis of Cross Section and Panel Data. Cambridge, MA: MIT Press.

Yates, B. T. (1981) Testimony of the American Psychological Association on the subject of effectiveness and cost-benefit of outpatient mental health services. Congressional Record, Serial No. 97-11, 124-130.

Yates, B. T. (1996) Analyzing costs, procedures, processes, and outcomes in human services: An introduction. Thousand Oaks, CA: Sage.

Yates, B.T. (1999) Measuring and improving cost, cost-effectiveness, and cost-benefit for substance abuse treatment programs. Bethesda, MD: National Institute on Drug Abuse, NIH Publication Number 99-4518.

Youth Law Center (2016) Quality Parenting Initiative [Accessed 19 December 192017 at http:// www.ylc.org/our-work/action-litigation/quality-foster-care/quality-parenting-initiative/] 

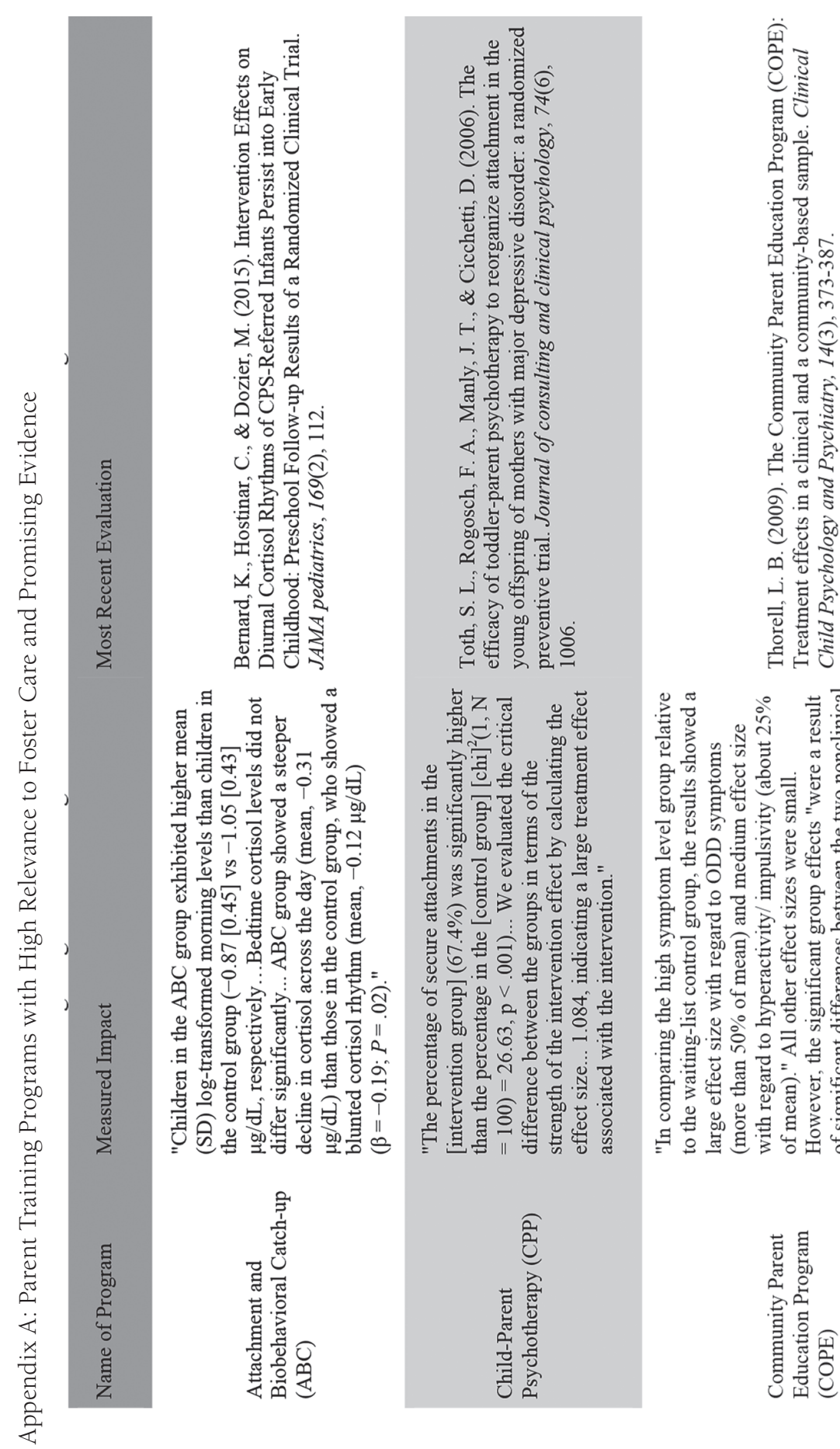

寻范岕总

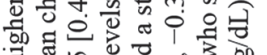

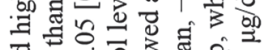

氖式 导

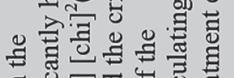

$\Xi$ そ

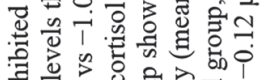

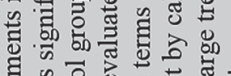

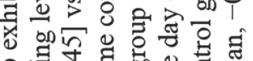

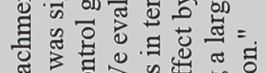

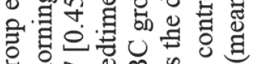

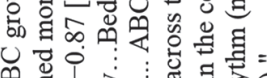

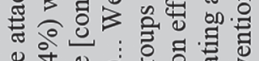

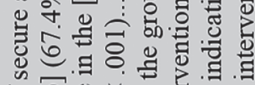

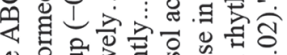

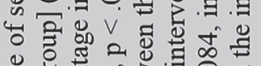

世

施㻤

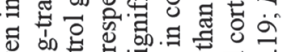

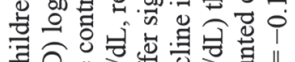

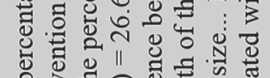

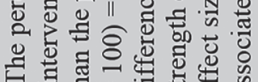

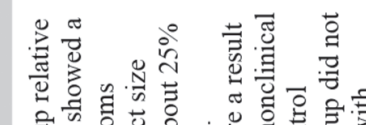

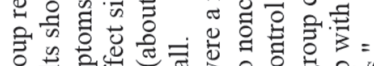

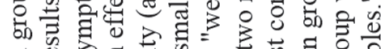

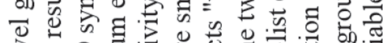

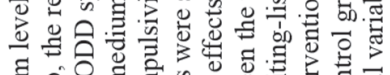

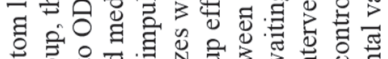

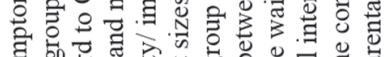

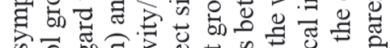

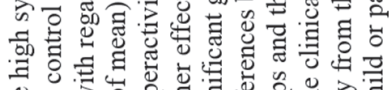

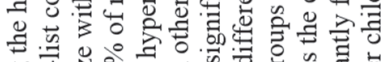

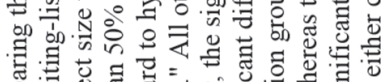

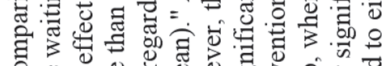

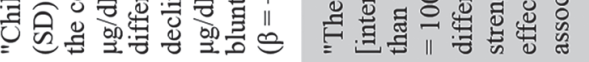

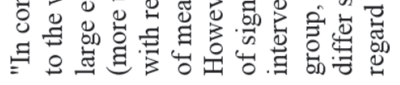
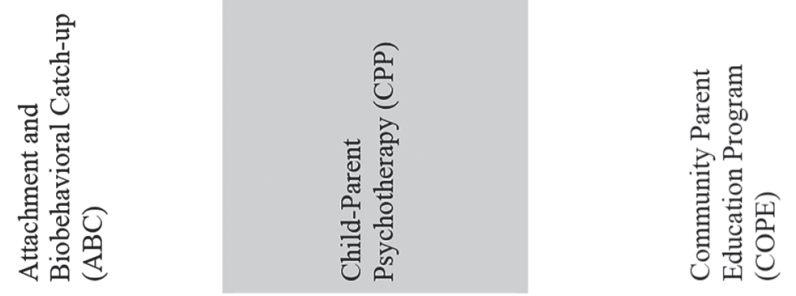

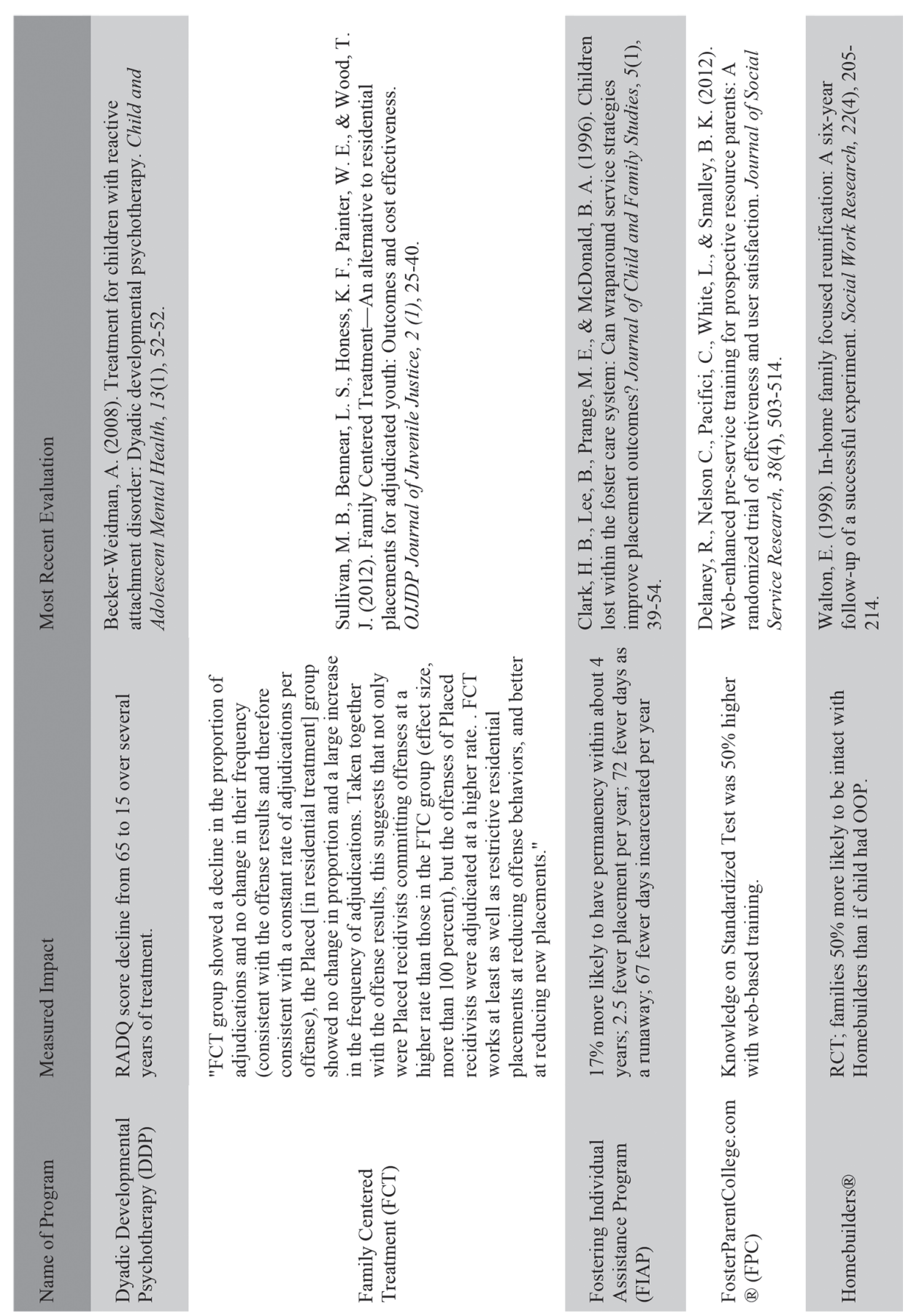


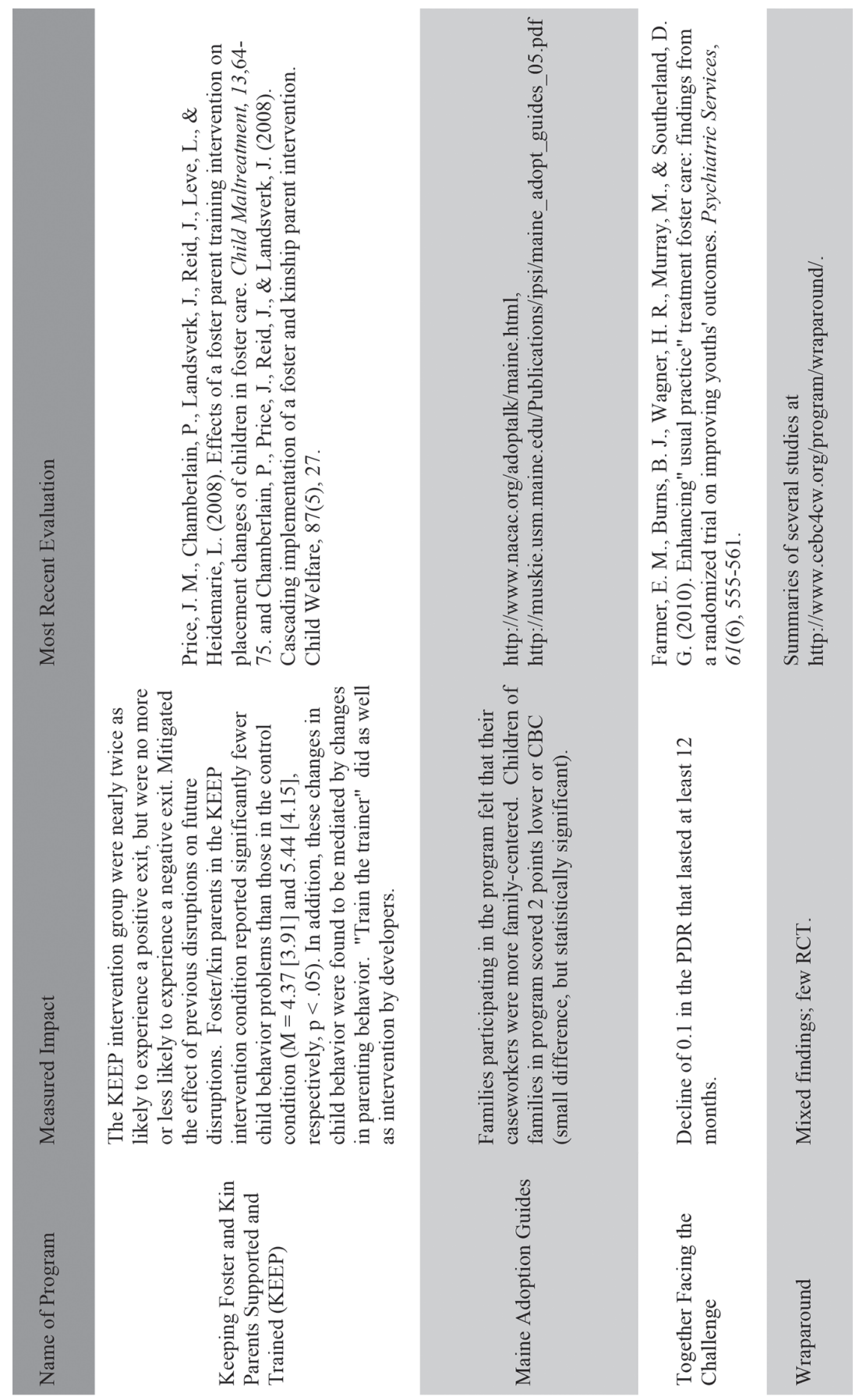


Appendix B: Focus Group Recruitment Email

\section{Dear QPI Leader:}

Hi! You may remember [Author] from April's QPI conference. Well, the Annie E. Casey foundation has asked her and me, [Author], of [Authors' Institutions], to study the economic benefits of QPI.

We include in our work the costs of QPI, the specific activities of QPI, changes that QPI makes in how foster parents view themselves and their roles and agency workers' relationships with foster parents, and the outcomes of QPI-both economic and other improvements that QPI causes.

Your participation in our study can help QPI and foster parents in several ways, including potentially improved funding of QPI and similar efforts.

Could at least one of your program's staff participate in a teleconference with [Authors] for 30 to 60 minutes on the Tuesday or Thursday following Memorial Day? I'm sorry this is so soon ... we are anxious to get our study rolling so we can report soon back to Annie E. Casey!

We are scheduling teleconferences for:

- Tuesday and Thursday noon-1 PM in Florida (9-10 AM in Nevada) and

- Tuesday and Thursday 4-5 PM in Florida (1-2 PM in Nevada).

Participation could be just listening in and email comments later to [Authors] or chiming in during the call with feedback on our very preliminary model of the resources, activities, processes, and monetary as well as nonmonetary outcomes of QPI.

Thank you in advance for your time, your energy, and your valuable insights.

[Authors] 


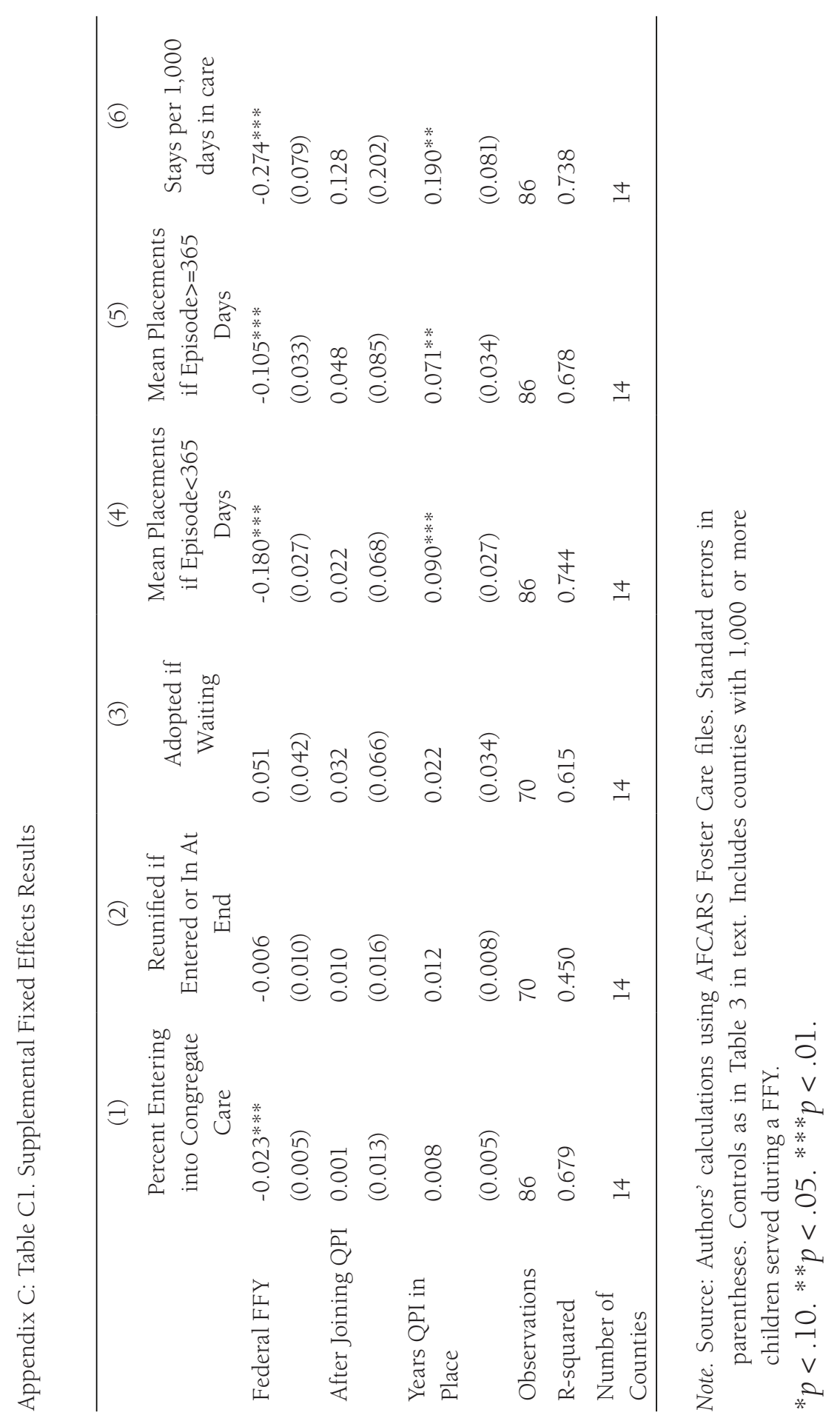




\section{Appendix D}

Supplemental Results for PSM Models

Table D1

First Stage Results for PSM Model in Table 4 in Text

\begin{tabular}{|c|c|c|}
\hline & $\begin{array}{c}\text { Average Days } \\
\text { if Reunified }\end{array}$ & $\begin{array}{l}\text { Average Days } \\
\text { if Adopted }\end{array}$ \\
\hline \multirow[t]{2}{*}{ Female } & -0.0233 & -0.0355 \\
\hline & $(0.0158)$ & $(0.0226)$ \\
\hline \multirow[t]{2}{*}{ Under age 6} & $0.0811^{* * *}$ & $0.1114 * * *$ \\
\hline & $(0.0181)$ & $(0.0280)$ \\
\hline \multirow[t]{2}{*}{ Over age 12} & -0.0330 & 0.0655 \\
\hline & $(0.0255)$ & $(0.0414)$ \\
\hline \multirow{2}{*}{ Child's race - Black } & $0.2316^{* * *}$ & $0.2346 * * *$ \\
\hline & $(0.0395)$ & $(0.0543)$ \\
\hline \multirow[t]{2}{*}{ Child's race - White } & $0.2355 * * *$ & $0.1504 * * *$ \\
\hline & $(0.0401)$ & $(0.0556)$ \\
\hline \multirow[t]{2}{*}{ Child's race - Other } & $0.2290 * * *$ & 0.1389 \\
\hline & $(0.0846)$ & $(0.1341)$ \\
\hline \multirow[t]{2}{*}{ Diagnosed disability } & $-0.5059 * * *$ & $0.2575 * * *$ \\
\hline & $(0.0723)$ & $(0.0442)$ \\
\hline \multirow[t]{2}{*}{ Mental retardation } & -0.1021 & $-0.3511^{* * *}$ \\
\hline & $(0.1249)$ & $(0.1105)$ \\
\hline \multirow[t]{2}{*}{ Other diagnosed condition } & $0.1569 *$ & $0.1862 * * *$ \\
\hline & $(0.0865)$ & $(0.0526)$ \\
\hline \multirow[t]{2}{*}{ Percent of life in system } & $-0.0550 *$ & $-0.4491 * * *$ \\
\hline & $(0.0332)$ & $(0.0486)$ \\
\hline \multirow[t]{2}{*}{ Removal reason - Drug abuse parent } & $-0.0763 * * *$ & $-0.0705^{* * *}$ \\
\hline & $(0.0177)$ & $(0.0241)$ \\
\hline \multirow[t]{2}{*}{ Removal reason - Drug abuse child } & $-0.1501^{* *}$ & $-0.3218 * * *$ \\
\hline & $(0.0679)$ & $(0.0732)$ \\
\hline \multirow[t]{2}{*}{ Removal reason - Neglect } & $-0.4834 * * *$ & $-0.6658 * * *$ \\
\hline & $(0.0188)$ & $(0.0297)$ \\
\hline
\end{tabular}




\begin{tabular}{|c|c|c|}
\hline Removal reason - Inadequate housing & $\begin{array}{l}0.0105 \\
(0.0235)\end{array}$ & $\begin{array}{l}-0.0356 \\
(0.0323)\end{array}$ \\
\hline Current placement - Group home & $\begin{array}{l}0.5349 * * * \\
(0.0347)\end{array}$ & \\
\hline Current placement - Institution & $\begin{array}{l}-0.4674 * * * \\
(0.0372)\end{array}$ & $\begin{array}{l}0.9092 * * * \\
(0.3269)\end{array}$ \\
\hline Current placement - Other & $\begin{array}{l}-0.6189 \\
(0.4232)\end{array}$ & $\begin{array}{l}-0.1037^{*} \\
(0.0631)\end{array}$ \\
\hline Duval & $\begin{array}{l}0.2962 * * * \\
(0.0450)\end{array}$ & $\begin{array}{l}0.5600 * * * \\
(0.0644)\end{array}$ \\
\hline Hillsborough & $\begin{array}{l}2.1786 * * * \\
(0.0356)\end{array}$ & $\begin{array}{l}2.2103 * * * \\
(0.0599)\end{array}$ \\
\hline Miami-Dade & $\begin{array}{l}1.1013 * * * \\
(0.0374)\end{array}$ & $\begin{array}{l}1.0340 * * * \\
(0.0615)\end{array}$ \\
\hline Orange & $\begin{array}{l}1.8005^{* * *} \\
(0.0398)\end{array}$ & $\begin{array}{l}1.9729 * * * \\
(0.0699)\end{array}$ \\
\hline Palm Beach & $\begin{array}{l}1.5967 * * * \\
(0.0391)\end{array}$ & $\begin{array}{l}1.7791 * * * \\
(0.0650)\end{array}$ \\
\hline Pasco & $\begin{array}{l}2.7458 * * * \\
(0.0578)\end{array}$ & $\begin{array}{l}2.7849 * * * \\
(0.0787)\end{array}$ \\
\hline Pinellas & $\begin{array}{l}1.8226 * * * \\
(0.0378)\end{array}$ & $\begin{array}{l}1.7845 * * * \\
(0.0643)\end{array}$ \\
\hline Polk & $\begin{array}{l}1.5397 * * * \\
(0.0395)\end{array}$ & $\begin{array}{l}1.6133 * * * \\
(0.0673)\end{array}$ \\
\hline Volusia & $\begin{array}{l}1.4009 * * * \\
(0.0451)\end{array}$ & $\begin{array}{l}1.6342 * * * \\
(0.0672)\end{array}$ \\
\hline Constant & $\begin{array}{l}-1.8706^{* * *} \\
(0.0530)\end{array}$ & $\begin{array}{l}-1.6319 * * * \\
(0.1037)\end{array}$ \\
\hline Observations & 33,735 & 16,277 \\
\hline Pseudo R-squared & 0.2320 & 0.2258 \\
\hline
\end{tabular}

Note. Standard errors in parentheses.

${ }^{*} p<.10 .{ }^{* *} p<.05 .{ }^{* *} p<.01$. 